\title{
HIV testing, HIV status and outcomes of treatment for tuberculosis in a major diagnosis and treatment centre in Yaounde, Cameroon: a retrospective cohort study
}

\author{
Eric Walter Pefura Yone ${ }^{1,2,4^{*}}$, Christopher Kuaban ${ }^{1,2}$ and André Pascal Kengne ${ }^{3}$
}

\begin{abstract}
Background: Human immuno-deficiency virus (HIV) infection and tuberculosis are common and often co-occurring conditions in sub-Saharan Africa (SSA). We investigated the effects of HIV testing and HIV status on the outcomes of tuberculosis treatment in a major diagnosis and treatment centre in Yaounde, Cameroon.

Methods: Participants were 1647 adults with tuberculosis registered at the Yaounde Jamot's Hospital between January and December 2009. Multinomial logistic regression models were used to relate HIV testing and HIV status to the outcomes of tuberculosis treatment during follow-up, with adjustment for potential covariates.

Results: Mean age of participants was 35.5 years (standard deviation: 13.2) and 938 (57\%) were men. Clinical forms of tuberculosis were: smear-positive (73.8\%), smear-negative (9.4\%) and extra-pulmonary (16.8\%). Outcomes of tuberculosis treatment were: cure/completion (68.1\%), failure (0.4\%), default (20.1\%), death (5.2\%) and transfer (6.3\%). Using cure/completion as reference, not testing for HIV was associated with adjusted odds ratio of 2.30 (95\% confidence interval: 1.65-3.21), 2.26 (1.29-3.97) and 2.69 (1.62-4.46) for the risk of failure/default, death and transfer respectively. The equivalents for a positive test among those tested (1419 participants) were $1.19(0.88-1.59), 6.35$ (3.53-11.45) and 1.14 (0.69-1.86).

Conclusions: Non-consent for HIV testing in this setting is associated with all unfavourable outcomes of tuberculosis treatment. However been tested positive was the strongest predictor of fatal outcome. Efforts are needed both to improve acceptance of HIV testing among patients with tuberculosis and optimise the care of those tested positive.
\end{abstract}

Keywords: Tuberculosis, HIV infection, Outcomes

\section{Background}

Human immunodeficiency virus (HIV) infection and tuberculosis are major health problems in sub-Saharan Africa (SSA). In 2009 alone, 35\% of the global 9.4 millions declared cases of tuberculosis (TB) were registered in Africa. In that same year, the rate of TB/HIV coinfection at the global level was 11-13\%, but was as high as $80 \%$ in Africa [1]. HIV infection favours the

\footnotetext{
* Correspondence: pefura2002@yahoo.fr

'Department of Internal Medicine and Subspecialties, Faculty of Medicine and Biomedical Sciences, University of Yaounde I, Yaounde, Cameroon

${ }_{2}^{2}$ Pneumology service, Yaounde Jamot Hospital, Yaounde, Cameroon

Full list of author information is available at the end of the article
}

reactivation and progression of latent Mycobacterium tuberculosis infection to overt tuberculosis infection, and Mycobacterium tuberculosis favours the replication of HIV and precipitates the natural course of the infection toward advanced stage or severe immune-depression $[2,3]$. Once tuberculosis becomes clinically manifest, coinfection with HIV is generally associated with poor outcome in SSA [4]. TB/HIV co-infection has been welldocumented in SSA with regard to smear-positive pulmonary tuberculosis [5-8]. The changing pattern with time has been described in places as well. In Cameroon for instance, the prevalence of HIV infection among those with smear-positive pulmonary tuberculosis 
increased from $16.6 \%$ in 1997 to about $29.3 \%$ in 2007 $[5,9]$. However, little is known about the prevalence of $\mathrm{HIV}$ in other clinical form of tuberculosis, as well as effects of HIV on the broad categories of outcomes of care for tuberculosis.

The current study has assessed the prevalence of HIV infection among African adults with tuberculosis, regardless of the clinical form, and quantified the effects of failure to test for HIV, and HIV status on the outcome of tuberculosis treatment in a major diagnosis and treatment centre in Cameroon.

\section{Methods}

\section{Study setting}

The study was conducted in the pneumology service of Yaounde Jamot's Hospital (YJH). The YJH serves a referral centre for tuberculosis and respiratory diseases for the capital city of Cameroon (Yaounde) and surrounding areas as described in detail elsewhere [10]. It is one of the major centres for diagnosis and treatment of tuberculosis (CDT) in Cameroon, and $\mathrm{YJH}$ also host an approved treatment centre for people living with HIV infection. From year 2006 to 2011, about 1600 to 1800 patients with tuberculosis were diagnosed and treated on an annual basis in this CDT. In the year 2009, up to $11 \%$ of all cases of tuberculosis diagnosed in the country were managed at the $\mathrm{YJH}$. Patients received at the CDT during January to December 2009 were considered for inclusion in the study. The study was approved by the institutional review board of the $\mathrm{YJH}$.

\section{Definition and classification of tuberculosis cases}

Patients who receive care at the CDT of YJH are consecutively registered as they are started on treatment. For those with a past exposure to antituberculosis treatment, the approach is nearly similar. Patients who report back to the centre with active tuberculosis and who have been treated in the past for at least one month are registered again with a new number and started on a standardised re-treatment regimen. The following international definitions are applied: [2,3,9] 1) smear-positive pulmonary tuberculosis $(\mathrm{PTB}+)$ - acid-fast bacilli (AFB) found in at least two sputum specimens; 2) smear-negative pulmonary tuberculosis (PTB-) - persisting negativity on three sputum examinations after ten-day course of nonspecific antibiotic treatment in a patient with tuberculosis-like clinical and radiological signs, and in the absence of any obvious cause; 3) extra-pulmonary tuberculosis (EPTB) - tuberculosis involving organs other than the lungs. Patients with past exposure to antituberculosis treatment are usually all smear-positive and are further classified as "relapse" (i.e. reoccurrence of the disease following a successful antituberculosis treatment course), "failure" (i.e. positive smear after five months of antituberculosis treatment) and "treatment after default" (i.e. starting antituberculosis treatment again after two consecutive months of interruption). A "new case" is a patient with tuberculosis who has never been exposed to antituberculosis treatment for more than one month in the past. "Other cases of tuberculosis" referred to patients who cannot fit in one of the categories described above.

\section{Detection and management of HIV infection}

At the CDT of the YJH, all patients with tuberculosis are screened for HIV infection free of charge after informed consent has been obtained from the patient or relative for dependant patients. This includes detection of antiHIV 1 and anti-HIV 2 antibodies in the serum with the use of two rapid tests: Determine ${ }^{\circledR}$ HIV $1 / 2$ (Abbot laboratories, Tokyo, Japan) and Immunocomb ${ }^{\circledR}$ II HIV 1 and 2 Bispot (Organics, Courbevoie, France). A patient is classified as HIV positive when the two tests are positive. For discordant tests, a confirmatory western blot test (New Lav Blot, Sanofi diagnostics-Pasteur) is conducted. All HIV-positive patients are started on prophylaxis with cotrimoxazole and those with CD4 count $<200 / \mathrm{mm}^{3}$ are started on highly active antiretroviral therapy free of charge. Initial antiretroviral regimens are the combinations lamivudine-zidovudine-efavirenz or lamivudinestavudine-efavirenz.

\section{Tuberculosis treatment}

Tuberculosis treatment at the CDT is made according to the guidelines of the Cameroon National Programme Against Tuberculosis (NPAT) and the WHO recommendations [11,12]. Patients are either admitted during the intensive phase of antituberculosis treatment, or treated as outpatient. Antituberculosis drugs are dispensed free of charge to all patients. Treatment regimens used are standard regimens of category I for new patients and of category II for re-treatment cases. New cases are treated with a regimen that includes an intensive phase of two months duration with rifampicin $(\mathrm{R})$, isoniazid $(\mathrm{H})$, ethambutol (E) and pyrazinamide (Z), followed by a 4month continuation phase with rifampicin and isoniazid (2RHEZ/4RH). During re-treatment, category I medications (R, H, E, Z) are completed with streptomycin (S). Therefore, re-treatment cases are treated with RHEZS for two months, followed by one month on RHEZ and five months on RHE (2RHEZS/1RHEZ/5RHE). During the intensive phase, adherence is directly monitored by the healthcare team for patients admitted, and during weekly drug collection in those treated as outpatients. The continuation phase is conducted on the outpatient basis and adherence assessed during monthly drugs collection visits. 


\section{Monitoring and outcomes of tuberculosis treatment}

During antituberculosis treatment, $\mathrm{PTB}+$ patients are re-examined for AFB at the end of month 2, 5 and 6 for new cases, and at the end of month 3, 5 and 8 in case of re-treatment. PTB- and patients with EPTB are monitored clinically and/or radiologically at the same frequency. At the end of the treatment, patients are ranked into mutually exclusive categories [13] as: 1) cured - patient with negative smear at the last month of treatment and at least one of the preceding; 2) treatment completed - patient who has completed the treatment and for whom the smear result at the end of the last month is not available; 3 ) failure - patient with positive smear at the $5^{\text {th }}$ month or later during treatment; 4) death death from any cause during treatment; 5) defaulter patient who's treatment has been interrupted for at least two consecutive months; 6) transfer - patient transferred to complete his treatment in another centre and who's treatment outcome is unknown.

\section{Data collection}

This was a retrospective cohort study among TB patients aged $\geq 15$ years. Tuberculosis treatment registers and antituberculosis treatment forms of the YJH's CDT served as basis for data collection for the study. Data were collected on age, sex, residence (urban vs. rural), history of exposure to antituberculosis treatment, localisation of tuberculosis infection, status for HIV infection, CD4 lymphocyte count (in those with HIV infection) and outcome of antituberculosis treatment. Cured and antituberculosis treatment completion were considered as favourable outcome (successful treatment) while death, default and failure were considered as unfavourable outcome [14].

\section{Statistical methods}

Data analysis used SPSS ${ }^{\circledR}$ v.12.0.1 for Windows ${ }^{\circledR}$ (SPSS Inc., Chicago, USA) and SAS/STAT ${ }^{\circledR}$ v 9.1 for windows (SAS Institute Inc., Cary, NC, USA). Results are presented as count (proportions), means (standard deviation, SD) or median (interquartile range, IQR). Group comparisons used chi square of Fisher exact test for qualitative variables, and Student t-test or Mann-Whitney $U$ test for quantitative variables. Multinomial Logistic regression models were used to investigate the effects of HIV testing and HIV status on the outcomes of tuberculosis in sex and age adjusted analysis, and after further adjustment for other potential confounders. A p-value $<0.05$ was used to characterise statistically significant results.

\section{Results}

\section{Study population}

During the year 2009, 1647 patients were screened and treated for tuberculosis at the Yaounde Jamot Hospital's
Centre for Diagnosis and Treatment. They were aged 33 years (interquartile range: $25-43$ years) and 938 (57\%) were men. Clinical forms of tuberculosis were: 1216 (73.8\%) for PTB+, 155 (9.4\%) for PTB- and 276 (16.8\%) for PTB (Table 1).

\section{Outcomes of TB}

In all, $272(16.5 \%)$ patients were cured and 849 (51.5\%) successfully completed the treatment, giving and overall treatment success rate of $68.1 \%$. Other outcomes of care were failure $(0.4 \%)$, death $(5.2 \%)$, default $(20.1 \%)$ and transfer $(6.1 \%)$. Characteristics of participants according to the outcomes of care are described in Table 1, showing some significant differences in the distribution by residence (urban vs. rural) and clinical forms of tuberculosis.

\section{HIV testing and status}

A total 1419 (86.2\%) patients were tested for HIV, and 497 (35\%) were positive for HIV, all for HIV-1 subtype. Of those tested positive, 229 (46.1\%) received antiretroviral therapy. Compared with those who did not test, patients who tested for HIV were borderline younger (35.3 vs. 37.0 years, $\mathrm{p}=0.06$ ), included more women (44.6\% vs. $33.3 \%, p=0.001)$, and more individuals with smear positive tuberculosis than with smear negative or extra-pulmonary tuberculosis $(75.8 \%, 8 \%, 16.2 \%$ vs. $61.8 \%, 18 \%$ and $20.2 \%, \mathrm{p}<0.001)$. Among participants tested for HIV, patients with positive status as compared with the negative ones were older (36 vs. 30 years, $\mathrm{p}<0.001)$, included more women $(57.1 \%$ vs. $37.3 \%$, $\mathrm{p}<0.001$ ), included fewer patients with smear positive than with smear negative and extra-pulmonary tuberculosis $(67.6 \%, 10.3 \%, 22.1 \%$ vs. $80.1 \%, 6.8 \%, 13 \%$, $\mathrm{p}<0.001)$. The distribution of participants according to whether they were tested for HIV and/or whether such test was positive varied significantly across outcome of care for tuberculosis (Table 1).

\section{Determinants of the outcomes of care}

In sex and age adjusted multinomial logistic regression analysis, and using the combined outcome of cure/ treatment completed (treatment success) as the reference, not testing for HIV was positively and significantly associated with treatment default/failure, deaths and transferred-out (Table 2). The range of effect was similar from these 3 broad outcomes. Among those tested for $\mathrm{HIV}$, a positive status was associated with an odds ratio (95\% confidence interval) of 6.40 (3.57-11.46) for mortality, but had no effect on other outcomes (Table 2). Similar range of effect was observed when participants with unknown status for HIV were compared with those with negative status $\left[\begin{array}{ll}6.49 & (3.26-12.93)\end{array}\right]$. In sex and age adjusted analysis, age was associated with mortality, 
Table 1 Characteristics of patients with tuberculosis according to the treatment outcome at the Jamot Hospital in 2009

\begin{tabular}{|c|c|c|c|c|c|c|c|c|}
\hline \multirow[t]{2}{*}{ Characteristics } & \multirow[t]{2}{*}{ Categories } & \multirow[t]{2}{*}{ Total } & \multicolumn{6}{|c|}{ Outcomes of tuberculosis treatment } \\
\hline & & & Cured/Completed* & Failure & Deaths & Defaulted & Transferred & P-value \\
\hline$N(\%)$ & & 1647 & $1121(68.1)$ & $6(0.4)$ & $86(5.2)$ & $331(20.1)$ & $103(6.3)$ & \\
\hline \multicolumn{9}{|l|}{ Age, years, $\mathrm{n}(\%)$} \\
\hline & $\leq 33$ & $854(51.9)$ & $609(71.3)$ & $2(0.2)$ & $24(2.8)$ & $172(20.1)$ & $47(5.5)$ & $<0.001$ \\
\hline & $>33$ & $793(48.1)$ & $512(64.6)$ & $4(0.5)$ & $62(7.8)$ & $159(20.1)$ & $56(7.1)$ & \\
\hline & Mean (SD) & $35.5(13.2)$ & $35.3(12.9)$ & $37.3(13.7)$ & $43.9(14)$ & $35.7(13.3)$ & $37.1(13.9)$ & $<0.001$ \\
\hline Men, n (\%) & & $938(57)$ & $635(67.7)$ & $4(0.4)$ & $50(5.3)$ & $194(20.7)$ & $55(5.9)$ & 0.467 \\
\hline Urban residence, $\mathrm{n}(\%)$ & & 1390/1622 (85.7) & $968(69.6)$ & $5(0.4)$ & $72(5.2)$ & $278(20)$ & $67(4.8)$ & $<0.001$ \\
\hline \multicolumn{9}{|l|}{ Clinical forms, n (\%) } \\
\hline & PTB+ & $1216(73.8)$ & $845(69.5)$ & $6(0.5)$ & $56(4.6)$ & $239(19.7)$ & $70(5.7)$ & $<0.001$ \\
\hline & PTB- & $155(9.4)$ & $86(55.5)$ & $0(0)$ & $16(10.3)$ & $42(27.1)$ & $11(7.1)$ & \\
\hline & EPTB & $276(16.8)$ & $190(68.8)$ & $0(0)$ & $14(5.1)$ & $50(3.7)$ & $22(8.0)$ & \\
\hline \multicolumn{9}{|l|}{ Type of patient, n (\%) } \\
\hline & New cases & 1505 (91.4) & $1026(68.2)$ & $5(0.3)$ & $81(5.4)$ & 295 (19.6) & $98(6.5)$ & 0.27 \\
\hline & Relapse & $119(7.2)$ & $81(68.1)$ & $1(0.8)$ & $5(4.2)$ & $28(23.5)$ & $4(3.4)$ & \\
\hline & Failure & $3(0.2)$ & $2(66.7)$ & $0(0)$ & $0(0)$ & $0(0)$ & $1(33.3)$ & \\
\hline & Defaulters & $20(1.2)$ & $12(60)$ & $0(0)$ & $0(0)$ & $8(40)$ & $0(0)$ & \\
\hline \multicolumn{9}{|l|}{ HIV serology, n (\%) } \\
\hline & Not done & $228(13.8)$ & $113(49.6)$ & $2(0.9)$ & $20(8.8)$ & $69(30.3)$ & $24(10.5)$ & $<0.001$ \\
\hline & Negative & $922 / 1419(65)$ & $685(74.3)$ & $4(0.4)$ & $17(1.8)$ & $166(18)$ & $50(5.4)$ & $<0.001$ \\
\hline & Positive & 497/1419 (35) & $323(65.0)$ & $0(0)$ & $49(9.8)$ & $96(19.3)$ & $29(5.8)$ & \\
\hline
\end{tabular}

SD, standard deviation; EPTB, extra-pulmonary tuberculosis ; PTB+, smear positive pulmonary tuberculosis ; PTB-, smear negative pulmonary tuberculosis; cured + completed $=$ therapeutic success.

urban residence with transfer-out, and SPTB- associated with death and treatment default/failure (Table 2).

In multivariable analysis, with further adjustment for residence and clinical form of tuberculosis, associations of HIV testing and HIV status with the outcome of treatment were largely similar to those observed in age and sex adjusted analysis, with only marginal attenuation of the effect sizes (Table 3). However, the global effect of clinical form of tuberculosis on the outcome of antituberculosis treatment was no longer significant ( $\mathrm{p}$-value $=$ 0.140 for the likelihood ratio test).

\section{Effects of HIV severity on the outcomes of tuberculosis treatment}

A subgroup of HIV positive patient (278) also had CD4 count data available. Figure 1 show the distribution of outcomes of tuberculosis care according to the stage of immune-depression in this subgroup. Mortality rate increased with decreasing CD4 count (CD4 count $<200$ / $\mathrm{mm}^{3}$ ) while treatment success was better in those with higher $\mathrm{CD} 4$ count $(\mathrm{p}=0.03$, Figure 1$)$.

\section{Discussion}

Our study from this historical diagnosis and treatment centre for tuberculosis in Cameroon has revealed the following major findings: 1) In spite of successive effort and several incentive, about one in eight patients still fails to get screen for HIV during active tuberculosis. 2) Among those tested, about a third is positive for HIV, with women being disproportionately affected. 3) Not testing for HIV or been tested positive are associated with similar excess mortality, and furthermore, not testing is associated with all poor outcomes of tuberculosis treatment.

The co-occurrence of HIV infection and tuberculosis is a well-known fact in Africa. Indeed, the re-emergence of tuberculosis in SSA over the last two decades largely mirrored the explosion of HIV epidemic in this region $[4,15]$. Most recent studies from Africa suggest that rates of TB/HIV co-infection range from $16 \%$ to about $80 \%$ [6,7,16-20]. In Asia where tuberculosis is also common, co-occurrence with HIV is found in less than $38 \%$ of patients $[1,21,22]$. In Cameroon, the prevalence of $\mathrm{TB} /$ HIV co-infection was $16.6 \%$ in 1997 [9], and further increased to $29.3 \%$ in 2007 [5] among patients with smear positive pulmonary tuberculosis, at the Yaounde Jamot's Hospital. This shift mirrors the rising trend of HIV infection at the community level in Yaounde, with prevalence rates increasing from $3 \%$ in 1994 [23] to $5.1 \%$ in 2007 [24]. 
Table 2 Sex and age adjusted predictors of the tuberculosis treatment outcome, odds ratio and $95 \%$ confidence interval

\begin{tabular}{|c|c|c|c|c|c|}
\hline & Cured/completed & Default/failure & Deaths & Tranferred & LR test ( $p$-value) \\
\hline Age, per year & 1 (reference) & $1.01(1.00-1.02)$ & $1.05(1.03-1.06)$ & $1.02(1.00-1.03)$ & $<0.001$ \\
\hline Sex, men vs. women & 1 (reference) & $1.07(0.83-1.37)$ & $0.91(0.58-1.43)$ & $0.83(0.56-1.26)$ & 0.717 \\
\hline Residence, urban vs. rural & 1 (reference) & $1.16(0.81-1.66)$ & $1.03(0.55-1.94)$ & $3.56(2.26-5.62)$ & $<0.001$ \\
\hline Clinical forms & & & & & 0.032 \\
\hline PTB+ & 1 (reference) & 1 (reference) & 1 (reference) & 1 (reference) & \\
\hline EPTB & 1 (reference) & $1.11(0.79-1.56)$ & $1.00(0.54-1.86)$ & $0.74(0.45-1.24)$ & \\
\hline PTB- & 1 (reference) & $1.83(1.13-2.97)$ & $2.42(1.12-5.25)$ & $1.09(0.51-2.36)$ & \\
\hline Type of patient, new vs retreatment & 1 (reference) & $0.76(0.51-1.14)$ & $1.59(0.63-4.06)$ & $1.85(0.74-4.67)$ & 0.13 \\
\hline HIV serology & & & & & $<0.001$ \\
\hline Negative & 1 (reference) & 1 (reference) & 1 (reference) & 1 (reference) & \\
\hline Positive & 1 (reference) & $1.19(0.89-1.59)$ & $6.37(3.55-11.41)$ & $1.14(0.70-1.86)$ & \\
\hline Not done & 1 (reference) & $2.51(1.78-3.53)$ & $6.49(3.26-12.93)$ & $2.87(1.69-4.86)$ & \\
\hline HIV test, not done vs. done & 1 (reference) & $2.37(1.70-3.28)$ & $2.48(1.43-4.31)$ & $2.79(1.69-4.60)$ & $<0.001$ \\
\hline HIV serology*, Positive vs Negative & 1 (reference) & $1.19(0.89-1.60)$ & $6.40(3.57-11.46)$ & $1.13(0.69-1.85)$ & $<0.001$ \\
\hline
\end{tabular}

PTB+, smear positive pulmonary tuberculosis ; EPTB, extra-pulmonary tuberculosis ; PTB-, smear negative pulmonary tuberculosis; LR, likelihood ratio ; *only in the subgroup of participants with test done.

The high prevalence of HIV in patients with extrapulmonary tuberculosis has been described elsewhere $[6,25,26]$. Our findings therefore are largely in agreement with published literature. Similarly, patients with SPTBwere more likely to be HIV positive than those with SPTB+. Unlike patients with tuberculosis and without HIV, those with HIV are likely to have lung lesions without cavitations [4,27], and accordingly negative smear [28].

We found that not testing for HIV or been tested positive were associated with similar range of risks for allcause mortality. This in some ways reflects the similarity of profile between patients not tested and those tested positive, and may further suggest that a consistent number of those not tested would have been HIV positive individuals, and perhaps with advanced stage of the disease. Furthermore, those patients who were not tested for HIV were likely those who will default or who will be transferred-out which is also full of significance. One explanation would be that failure to get tested for HIV in this setting is a simple and reliable indicator of future poor adherence to antituberculosis treatment. Another explanation could be that, non-consent for HIV test

Table 3 Multivariable adjusted predictors of the tuberculosis treatment outcome, odds ratio and $95 \%$ confidence interval

\begin{tabular}{|c|c|c|c|c|c|}
\hline & Cured/completed & Default/failure & Deaths & Tranferred & LR test (p-value) \\
\hline Age, per year & 1 (reference) & $1.00(0.99-1.02)$ & $1.04(1.03-1.06)$ & $1.01(0.99-1.02)$ & $<0.001$ \\
\hline Sex, men vs. women & 1 (reference) & $0.98(0.76-1.27)$ & $0.89(0.56-1.41)$ & $0.69(0.45-1.05)$ & 0.372 \\
\hline Residence, urban vs. rural & 1 (reference) & $1.21(0.84-1.74)$ & $1.10(0.58-2.01)$ & $3.81(2.39-6.06)$ & $<0.001$ \\
\hline Clinical forms & & & & & 0.140 \\
\hline PTB+ & 1 (reference) & 1 (reference) & 1 (reference) & 1 (reference) & \\
\hline EPTB & 1 (reference) & $1.21(0.85-1.73)$ & $1.08(0.58-2.02)$ & $0.82(0.48-1.40)$ & \\
\hline PTB- & 1 (reference) & $1.86(1.13-3.01)$ & $2.08(0.94-4.60)$ & $1.18(0.53-2.60)$ & \\
\hline Type of patient, new vs retreatment & 1 (reference) & $0.73(0.48-1.11)$ & $1.43(0.56-3.68)$ & $1.64(0.64-4.20)$ & 0.20 \\
\hline HIV serology & & & & & $<0.001$ \\
\hline Negative & 1 (reference) & 1 (reference) & 1 (reference) & 1 (reference) & \\
\hline Positive & 1 (reference) & $1.19(0.89-1.59)$ & $6.43(3.57-11.57)$ & $1.13(0.95-1.85)$ & \\
\hline Not done & 1 (reference) & $2.44(1.73-3.45)$ & $6.09(3.02-12.28)$ & $2.76(1.62-4.72)$ & \\
\hline HIV test, not done vs. done & 1 (reference) & $2.30(1.65-3.21)$ & $2.26(1.29-3.97)$ & $2.69(1.62-4.46)$ & $<0.001$ \\
\hline HIV serology*, Positive vs Negative & 1 (reference) & $1.19(0.88-1.59)$ & $6.35(3.53-11.45)$ & $1.14(0.69-1.86)$ & $<0.001$ \\
\hline
\end{tabular}

PTB+, smear positive pulmonary tuberculosis ; EPTB, extra-pulmonary tuberculosis ; PTB-, smear negative pulmonary tuberculosis; LR, likelihood ratio; ${ }^{\circ}$ only in the subgroup of participants with the test done. 


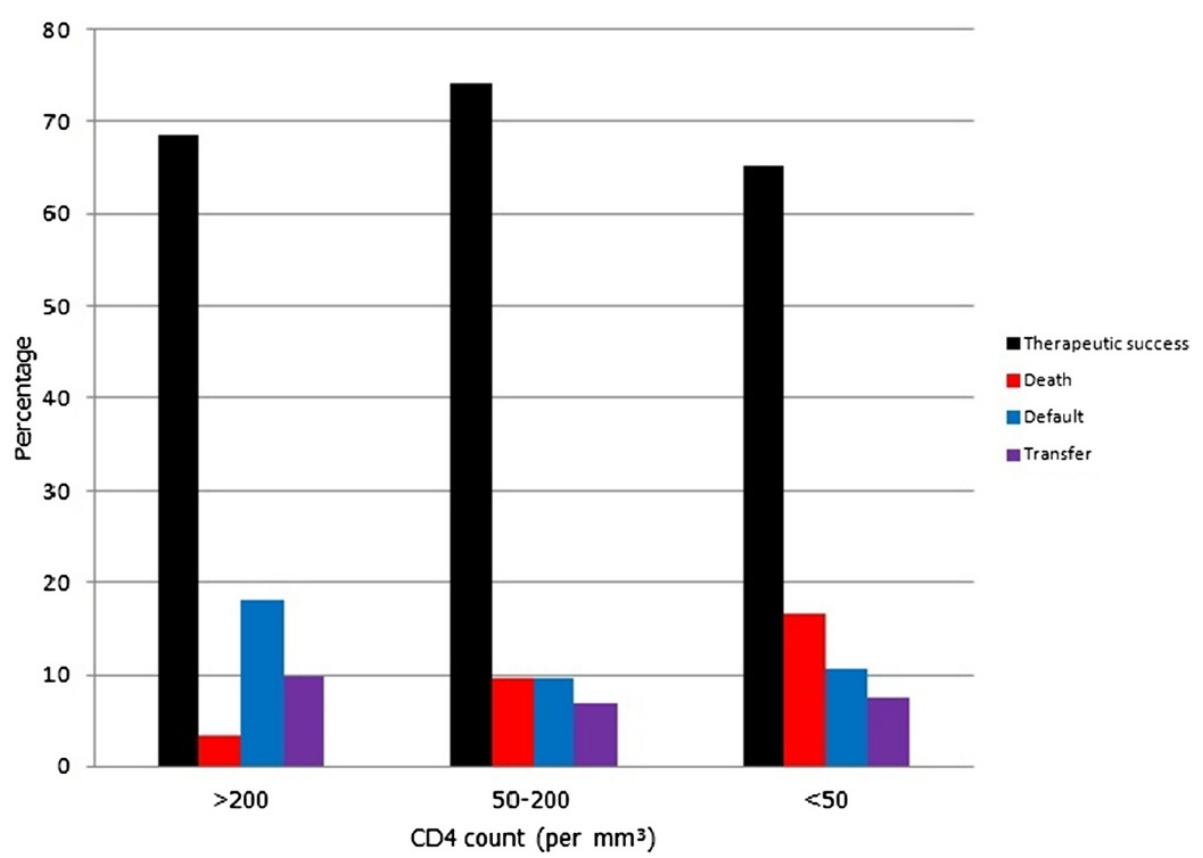

Figure 1 CD4 count and outcome of tuberculosis treatment among HIV positive patients. Therapeutic success, Death, Defaulted, Transferred.

affects the attitude of the healthcare team toward the patient, with renewed invitations to the patient to accept the test. Under such a pressure, patients would either abandon the treatment or request for their discharge or transfer to another centre.

This study has some limitations. Among the subgroup of patients tested positive for HIV, not everyone had CD4 count, and therefore we were unable to fully account for the possible effect of advanced stage of HIV infection on the outcome of care for tuberculosis. We've got no suggestion that missing CD4 count would occur in a differential way to affect the validity of our findings. That no systematic effort was in place to trace patients who dropped out during the year of the study has probably introduced some biases in our ranking of patients according to the outcome of care. For instance, some patients who died in-between antituberculosis treatment drug collection visits would have been inappropriately classified as drop-out. However, the effects of misclassification if any would need to be very important to invalidate our findings.

Our study also has major strengths. These include our large sample size, including the totality of adults patients followed at the CDT during the year of the study. The choice of analytic methods has also allowed us to examine the effects of HIV testing and HIV status on the broad range of outcome of tuberculosis treatment, which is what many previous investigators have not done.

\section{Conclusions}

HIV infection is frequent among patients with active tuberculosis in this setting and disproportionately affects women. Both not testing for HIV and been tested positive confer a high risk of mortality in our patients with tuberculosis. In addition, not testing for tuberculosis is associated with poor outcomes of tuberculosis. Efforts are needed to improve the acceptance of HIV testing among patients with tuberculosis and reduce mortality risk among those tested positive in our context.

\section{Abbreviations}

AFB: Acid-fast bacilli; CDT: Centre for diagnosis and treatment of tuberculosis; E: Éthambutol; EPTB: Extra-pulmonary tuberculosis; H: Isoniazid; HIV: Human immunodeficiency virus; NPAT: National programme against tuberculosis;

PTB-: Smear-negative pulmonary tuberculosis; PTB+: Smear-positive pulmonary tuberculosis; R: Rifampicin; S: Streptomycin; SSA: Sub-Saharan Africa; TB: Tuberculosis; YJH: Yaounde Jamot's Hospital; Z: Pyrazinamide.

\section{Competing interests}

The authors declare that they have no competing interests.

\section{Authors' contributions}

EWPY conceived the study, supervised data collection, co-analysed the data and drafted of the manuscript; CK supervised the data collection and critically revised the manuscript; APK contributed to study designed, data analysis, drafting and critical revision of the manuscript. All authors read and approved the final manuscript.

\section{Author details}

${ }^{1}$ Department of Internal Medicine and Subspecialties, Faculty of Medicine and Biomedical Sciences, University of Yaounde I, Yaounde, Cameroon.

${ }^{2}$ Pneumology service, Yaounde Jamot Hospital, Yaounde, Cameroon. ${ }^{3}$ South African Medical Research Council \& University of Cape Town, Cape Town, South Africa. ${ }^{4}$ Yaounde Jamot's Hospital, P.O Box: 4021, Yaounde, Cameroun. 
Received: 26 November 2011 Accepted: 20 June 2012

Published: 15 August 2012

\section{References}

1. WHO report. Global tuberculosis control; 2010. http://whqlibdoc.who.int/ publications/2010/.

2. Mariani F, Goletti D, Ciaramella A, Martino A, Colizzi V, Fraziano M: Macrophage response to Mycobacterium tuberculosis during HIV infection: relationships between macrophage activation and apoptosis. Curr Mol Med 2001, 1:209-216.

3. Rosas-Taraco AG, Arce-Mendoza AY, Caballero-Olín G, Salinas-Carmona MC Mycobacterium tuberculosis upregulates coreceptors CCR5 and CXCR4 while HIV modulates CD14 favoring concurrent infection. AIDS Res Hum Retroviruses 2006, 22:45-51.

4. Maartens G, Wilkinson RJ: Tuberculosis. Lancet 2007, 370:2030-2043.

5. Kuaban C, Bame R, Mouangue L, Djella S, Yomgni C: Non conversion of sputum smears in new smear positive pulmonary tuberculosis patients in Yaoundé, Cameroon. East Afr Med J 2009, 86:219-225.

6. Sume GE, Etogo D, Kabore S, Gnigninanjouena O, Epome SS, Metchendje $\mathrm{JN}$ : Seroprevalence of human immunodeficiency virus infection among tuberculosis patients in the Nylon district hospital tuberculosis treatment centre. East Afr Med J 2008, 85:529-536.

7. van der Werf MJ, Sebhatu M, Weldegergis T, Tesfazion A, Borgdorff MW: TB-HIV co-infection in Eritrea. Int J Tuberc Lung Dis 2007, 11:823-826.

8. Dagnra AY, Adjoh K, Tchaptchet Heunda S, Patassi AA, Sadzo Hetsu D, Awokou F, Tidjani O: Prevalence of HIV-TB co-infection and impact of HIV infection on pulmonary tuberculosis outcome in Togo. Bull Soc Pathol Exot 2010. doi:10.1007/s13149-010-0079-3.

9. Kuaban C, Bercion R, Koulla-Shiro S: HIV seroprevalence rate and incidence of adverse skin reactions in adults with pulmonary tuberculosis receiving thiacetazone free anti tuberculosis treatment in Yaounde, Cameroon. East Afr Med J 1997, 74:474-477.

10. Pefura Yone EW, Kengne AP, Kuaban C: Incidence, time and determinants of tuberculosis treatment default in Yaounde, Cameroon: a retrospective hospital register-based cohort study. BMJ Open 2011, 1:e000289.

11. Aït-Khaled N, Alarcón E, Armengol R, Bissell K, Boillot F, Caminero JA, Chiang CY, Clevenbergh P, Dlodlo R, Enarson DA, Enarson P, Fujiwara PI, Harries AD, Heldal E, Hinderaker SG, Monedero I, Rieder HL, Rusen ID, Trébucq A, Van Deun A, Wilson N: Prise en charge de la tuberculose. Guide des éléments essentiels pour une bonne pratique. Paris: Union Internationale Contre la Tuberculose et les Maladies Respiratorires; 2010.

12. Programme National de Lutte contre la Tuberculose: Guide Technique pour le personnel de santé. Yaoundé: Ministère de la Santé Publique du Cameroun; 2004.

13. Organisation Mondiale de la Santé: Le traitement de la tuberculose: Principes à l'intention des programmes nationaux. Genève: Organisation mondiale de la Santé; 2003

14. Zellweger JP, Coulon P: Outcome of patients treated for tuberculosis in Vaud County, Switzerland. Int J Tuberc Lung Dis 1998, 2:372-377.

15. Corbett EL, Marston B, Churchyard GJ, De Cock KM: Tuberculosis in sub-Saharan Africa: opportunities, challenges, and change in the era of antiretroviral treatment. Lancet 2006, 367:926-937.

16. Ige OM, Sogaolu OM, Ogunlade OA: Pattern of presentation of tuberculosis and the hospital prevalence of tuberculosis and HIV co-infection in University College Hospital, Ibadan, a review of five years (1998-2002). Afr J Med Sci 2005, 34:329-333.

17. Maher D, Harries A, Getahun H: Tuberculosis and HIV interaction in Sub-Saharan Africa: impact on patients and programmes, implications for policies. Trop Med Int Health 2005, 10:734-742.

18. Nkoghe D, Toung Mve M, Nnegue S, Okome Nkoume M, Iba BJ, Hypolite J, Leonard $\mathrm{P}$, Kendjo E: Séroprévalence du VIH au sein des tuberculeux de I'hôpital de Nkembo à Libreville, Gabon. Bull Soc Pathol Exot 2005, 98:121-122.

19. Ollé-Goig JE: Tuberculosis in rural Uganda. Afr Health Sci 2010, 10:226-229.

20. Habib AG: A clinical and epidemiologic update on the interaction between tuberculosis and human immunodeficiency virus infection in adults. Ann Afr Med 2009, 8:147-155.

21. Cain KP, Kanara N, Laserson KF, Vannarith C, Sameourn K, Samnang K, Qualls ML, Wells CD, Varma JK: The epidemiology of HIV-associated tuberculosis in rural Cambodia. Int J Tuberc Lung Dis 2007, 11:1008-1013.
22. Pontororing GJ, Kenangalem E, Lolong DB, Waramori G, Sandjaja, Tjitra E, Price RN, Kelly PM, Anstey NM, Ralph AP: The burden and treatment of HIV in tuberculosis patients in Papua Province, Indonesia: a prospective observational study. BMC Infect Dis 2010, 10:362

23. AIDS epidemic update. UNAIDS/WHO; 2008. http://data.unaids.org/pub/ Report/2008/jc1535_annual_report07_fr.pdf.

24. Ministry of Public Health: Report on HIV sentinel surveillance system in Cameroon. Yaounde: Ministry of Public Health of Cameroon; 1994.

25. Sharma SK, Mohan A: Extrapulmonary tuberculosis. Indian J Med Res 2004, 120:316-353.

26. Golden MP, Vikram HR: Extrapulmonary tuberculosis: an overview. Am Fam Physician 2005, 72:1761-1768.

27. Aderaye G, Bruchfeld J, Assefa G, Feleke D, Källenius G, Baat M, Lindquist L: The relationship between disease pattern and disease burden by chest radiography, M. tuberculosis Load, and HIV status in patients with pulmonary tuberculosis in Addis Ababa. Infection 2004, 32:333-338.

28. Mugusi F, Villamor E, Urassa W, Saathoff E, Bosch RJ, Fawzi WW: HIV coinfection CD4 cell counts and clinical correlates of bacillary density in pulmonary tuberculosis. Int J Tuberc Lung Dis 2006, 10:663-669.

doi:10.1186/1471-2334-12-190

Cite this article as: Pefura Yone et al:: HIV testing, HIV status and outcomes of treatment for tuberculosis in a major diagnosis and treatment centre in Yaounde, Cameroon: a retrospective cohort study. BMC Infectious Diseases 2012 12:190.

\section{Submit your next manuscript to BioMed Central and take full advantage of:}

- Convenient online submission

- Thorough peer review

- No space constraints or color figure charges

- Immediate publication on acceptance

- Inclusion in PubMed, CAS, Scopus and Google Scholar

- Research which is freely available for redistribution

Submit your manuscript at www.biomedcentral.com/submit
C Biomed Central 